\title{
Educação intergeracional, na sociedade do conhecimento: agenda europeia e
}

\author{
políticas nacionais
}

\section{Intergenerational education in the knowledge society: European agenda and national policies}

\author{
Maria Patrício*, António Osório** \\ *Instituto Politécnico de Bragança, **Universidade do Minho
}

\begin{abstract}
Resumo
Reconhecendo a importância que a aprendizagem intergeracional tem em todos os domínios da sociedade em geral e da educação em particular, este trabalho pretende responder às seguintes perguntas: que lugar tem a educação intergeracional na agenda europeia, na sociedade do conhecimento? Que influência tem nas políticas educativas nacionais? A análise de documentos que orientam as políticas europeias e nacionais em relação à intergeracionalidade e ao impacto na educação permitiu concluir que não existem políticas educativas concretas impulsionadoras de uma abordagem intergeracional que contemple as tecnologias.

Palavras chave: educação intergeracional, políticas educativas, agenda europeia, tecnologias digitais de informação e conhecimento, aprendizagem ao longo da vida.
\end{abstract}

\begin{abstract}
Recognizing the importance of intergenerational learning in all domains of society in general and in education in particular, this paper intends to answer the following questions: what is the place of intergenerational education in the European agenda in the knowledge society? What influence does it have on national educational policies? The analysis of documents that guide the European and national policies in relation to intergenerationality and the impact on education allowed to conclude that there are no concrete educational policies driving an intergenerational approach attending technologies.

Keywords: intergenerational education, educational policy, European agenda, digital technologies of information and knowledge, lifelong learning.
\end{abstract}

Em 2012 o Ano Europeu do envelhecimento ativo e da solidariedade entre gerações colocou na ordem do dia as questões do envelhecimento ativo e da intergeracionalidade e teve como objetivos responder aos desafios de uma sociedade europeia envelhecida e reduzir o risco do conflito geracional. Procurou, igualmente, chamar a atenção para os desafios das mudanças demográficas e sociais e para a importância do contributo dos idosos na sociedade, bem como incentivar os decisores políticos e todas as partes interessadas na tomada de medidas para a criação de condições necessárias ao envelhecimento ativo e ao reforço da solidariedade entre as gerações. Na sequência de uma investigação sobre o uso das tecnologias digitais da sociedade do conhecimento em contexto intergeracional, constatamos que a aprendizagem intergeracional é de extrema relevância em todos os domínios da sociedade em geral e da educação em particular. Porém, há um vazio em termos de políticas educativas intergeracionais. Deste modo, este trabalho pretende responder às seguintes perguntas: que lugar tem a educação intergeracional na agenda europeia, na sociedade do conhecimento? Que influência tem nas políticas educativas nacionais? Problematizar o que tem sido desenvolvido na área da educação intergeracional, implica ter em conta as diferentes orientações e princípios que têm fundamentado a atuação estatal nesta matéria e o modo como tem sido percecionada pelas entidades europeias, assim como as respetivas orientações, servindo de referência à análise do contexto português. Pretende-se, assim, aferir as políticas e estratégias educativas impulsionadoras de uma abordagem intergeracional que contemple a função das tecnologias digitais emergentes, nas formas de aprender ao longo de toda a vida das pessoas. Procura-se, também, indagar de que modo a promoção de dinâmicas intergeracionais com tecnologias digitais de informação e conhecimento permite intensificar (ou não) as relações entre gerações, promover o envelhecimento ativo e perspetivar novas práticas de aprendizagem ao longo da vida. Na sua estrutura, o artigo apresenta os principais procedimentos metodológicos que orientaram a recolha de dados, seguido da sua apresentação e análise, para depois passar à discussão de modo a responder às perguntas de investigação.

\section{Metodologia}

A metodologia que orienta este estudo é de natureza qualitativa, de corte interpretativo, com vista a identificar convergências e tensões entre as políticas europeias e nacionais. $\mathrm{O}$ período que dedicamos à pesquisa foi entre 2012 e 2017, abrangendo assim o Ano Europeu 2012 e a atualidade, através da análise de documentos que orientam as políticas europeias e nacionais em relação à 
intergeracionalidade e ao impacto direto sobre a educação.

$\mathrm{Na}$ procura de resposta para as questões que propusemos, selecionamos documentos orientadores importantes nesta matéria que, eventualmente, fizessem referência à educação intergeracional.

Para o contexto europeu selecionamos os seguintes documentos:

- Declaração do Conselho sobre o Ano Europeu do Envelhecimento Ativo e da Solidariedade entre as Gerações (2012): Perspetivas (Conselho da União Europeia, 2012);

- Relatório conjunto de 2015 do Conselho e da Comissão sobre a aplicação do quadro estratégico para a cooperação europeia no domínio da educação e da formação (EF 2020) (Jornal Oficial da União Europeia, 2015);

- A new skills agenda for Europe - working together to strengthen human capital, employability and competitiveness 2016 (European Commission, 2016).

E, para o contexto português, analisamos:

- Resolução da Assembleia da República n. ${ }^{\circ}$

66/2012 (Diário da República, 8 de maio de 2012);

- Programa do XXI Governo Constitucional 2015-2019 (Governo de Portugal, 2015);

- Estado da Educação 2015 (Conselho Nacional de Educação, 2016);

- Relatório de Portugal do terceiro ciclo de revisão e avaliação da estratégia de implementação regional do Plano Internacional de Ação de Madrid sobre o Envelhecimento (Ministério do Trabalho Solidariedade e Segurança Social, março de 2017).

Os dados recolhidos foram tratados através da análise de conteúdo, que corresponde a "um conjunto de técnicas de análise das comunicações, que utiliza procedimentos sistemáticos e objetivos de descrição do conteúdo das mensagens" (Bardin, 2014, p. 33), com o objetivo de compreender o que os dados dizem sobre a realidade estudada.

\section{Análise dos dados}

Os documentos selecionados foram analisados e organizados em duas categorias: 1) políticas europeias: educação intergeracional; 2) políticas nacionais: educação intergeracional. $\mathrm{Na}$ análise aos documentos tivemos por critério a frequência das palavras seguintes: educação; intergeracional; gerações; tecnologias digitais; solidariedade; envelhecimento ativo; e aprendizagem ao longo da vida. $\mathrm{O}$ cruzamento destas informações permite encontrar pontos concordantes e divergentes.

Políticas europeias: educação intergeracional. Tendo em consideração os documentos em estudo, salienta-se que o Ano Europeu 2012 contribuiu para sensibilizar a sociedade em geral para as questões do envelhecimento demográfico e das suas oportunidades. Parece ter-se gerado uma dinâmica política determinando princípios orientadores para o envelhecimento ativo e a solidariedade entre gerações, nas áreas do emprego, da participação na sociedade e da vida independente, fomentando a coesão social, a inclusão e a prosperidade de todas as gerações. E, de acordo com o Conselho da União Europeia (2012) o envelhecimento ativo e a solidariedade entre gerações exigem, entre outras medidas, "a promoção da participação no mercado de trabalho, mediante iniciativas que envolvam os mais novos e os mais velhos em atividades de formação e de aprendizagem ao longo da vida, o que favorece a transmissão intergeracional de conhecimento" (p. 4).

A educação e a formação, enquanto setores favoráveis ao crescimento, assumem um papel fundamental na Estratégia Europa 2020, com 6 domínios prioritários, respetivas questões concretas e prioridades específicas, ao nível da formação profissional e da educação de adultos. É neste âmbito que vemos inscritos um conjunto de objetivos que visam melhorar as literacias dos adultos, incluindo a literacia digital, a aprendizagem em contexto laboral e ao longo da vida, através da implementação da agenda renovada no domínio da educação de adultos.

A Nova Agenda de Competências para a Europa convida os Estados-membros a melhorar a qualidade e os níveis de competências, promovendo as competências transversais e a sua relevância para o mercado de trabalho, o que contribuirá para aumentar a empregabilidade, a competitividade e o crescimento na Europa. A Comissão propõe 10 ações para melhorar as competências dos cidadãos europeus, das quais destacamos para a nossa análise as competências digitais e o investimento na qualificação de adultos.

Políticas nacionais: educação intergeracional. Nos documentos nacionais é notória a convergência das políticas com as orientações europeias. A Assembleia da República recomenda ao Governo, no âmbito do Ano Europeu do envelhecimento ativo e da solidariedade entre gerações, Programa de Ação, 2012, o desenvolvimento de medidas concretas, entre as quais realçamos "a importância da sã convivência intergeracional para a melhoria da sociedade, quer seja em termos familiares, sociais ou laborais, tornando-a fraternalmente melhor" e "maior inclusão de novas tecnologias de informação e comunicação e networks na geração acima dos 65 anos" (Diário da República, 8 de maio de 2012, p. 2427).

O programa do Governo (2015) em funções, assenta numa estratégia de convergência com a União Europeia na resposta aos desafios económicos e sociais. Desafios que defendem a promoção da democratização da cultura científica e tecnológica com iniciativas várias, como o "Lançamento de um programa sistemático de apoio a projetos intergeracionais entre investigadores, estudantes do ensino superior e associações juvenis, com o objetivo de reforçar a cultura científica dos jovens e o debate intergeracional em torno do conhecimento" (p. 212), ou a dinamização de redes associativas que fomentem "atividades intergeracionais (cultura, desporto, etc.) e a transmissão intergeracional de competências" (p. 261).

No relatório sobre o Estado da Educação 2015 (Conselho Nacional de Educação, 2016) procurámos saber, por um lado, se as questões da intergeracionalidade têm sido consideradas na educação e, por outro, encontrar referencias à aprendizagem ao longo da vida e às TIC. Constatamos, sem surpresa, que não há qualquer tipo de 
menção à intergeracionalidade. Quanto à aprendizagem ao longo da vida, a expressão surge inscrita na designação da Agência Nacional para a Gestão do Programa de Aprendizagem ao Longo da Vida. De acordo com os dados, as TIC fazem parte da oferta de atividades de enriquecimento curricular para o $1 .^{\circ}$ Ciclo do Ensino Básico, sendo que o termo 'envelhecimento' figura apenas para evidenciar a tendência de envelhecimento da população e do corpo docente em todos os níveis de ensino.

Relativamente ao Relatório de Portugal do terceiro ciclo de revisão e avaliação da estratégia de implementação regional do Plano Internacional de Ação de Madrid sobre o Envelhecimento, os dados evidenciam que, globalmente, o envelhecimento tem sido um desafio nas diferentes áreas de atuação política com principal incidência em medidas de apoio ao trabalho, à solidariedade e à segurança social e à saúde. A transversalidade das políticas de envelhecimento assumidas no relatório, evidenciam preocupações de caráter educativo, como o acesso dos mais velhos à aprendizagem ao longo da vida e a promoção da solidariedade entre gerações através de projetos promotores do diálogo entre gerações e da aprendizagem intergeracional, ao nível da responsabilidade social de diversas entidades em contextos sociais e empresariais.

\section{Discussão}

As análises que reunimos convergem para a identificação de políticas que visam fazer face ao impacto do envelhecimento demográfico e relançar o crescimento económico e a coesão social.

De acordo com os dados examinados, julgamos poder afirmar que a dimensão intergeracional se encontra muito aquém do desejado, se analisada apenas numa perspetiva educativa. Não obstante, ainda que por força dos argumentos económicos e das preocupações de índole social, a solidariedade entre gerações tem sido promovida e incentivada em algumas políticas de respostas sociais e de saúde através de projetos e atividades desenvolvidos no âmbito de dinâmicas comunitárias e intergeracionais (hortas comunitárias, bandas filarmónicas, ateliers de culinária, teatro, apoio domiciliário, etc.).

A União Europeia, através do Programa de Aprendizagem ao Longo da Vida - Grundtvig, tem procurado responder aos desafios educacionais do envelhecimento da população na Europa e proporcionar aos adultos caminhos para melhorar os seus conhecimentos e competências, com o apoio a inúmeros projetos (mix@ges - Intergenerational Bonding via Creative New Media; The Knowledge Volunteers TKV; LEAGE - Learning Games for older Europeans; Intergenerational ICT Skills; Silver Project - Stimulating ICT Learning for Active EU Elders; GoACT project) promotores da aprendizagem intergeracional através do desenvolvimento de competências digitais. Estes projetos são excelentes, mas insuficientes sendo fundamental considerar, a nível de políticas educativas, todas as gerações e não apenas nas políticas económicas, de emprego e de solidariedade social. Assim, parece justificar-se alargar o âmbito de atuação ao setor da educação. Perspetivar a educação intergeracional implica, para além de uma abordagem intergeracional, um olhar integrado e multidimensional que não tem estado presente na organização da sociedade e nas respetivas políticas públicas. Verificamos que as instituições funcionam, predominantemente, em torno de questões muito específicas, arriscando separar gerações, encontrando-se, esporadicamente, atividades ou projetos intergeracionais.

\section{Considerações finais}

A análise documental realizada permite concluir que existem alguns esforços a nível europeu e nacional na implementação de políticas conducentes à promoção da solidariedade geracional, ainda que a nível de políticas educativas pouco tenha sido concretizado, pelo menos no campo da educação formal, havendo algumas experiências de cariz informal e não formal, mais de natureza social.

A educação intergeracional deve ser considerada numa perspetiva transversal pelas diferentes áreas das políticas públicas, a nível europeu, nacional e local, pensada de modo coerente e integrado para a construção de territórios inclusivos, participativos e solidários.

Assume ainda relevância o entender-se a aprendizagem ao longo da vida como estratégia promotora da interação entre gerações jovens e gerações idosas, da solidariedade social, do envelhecimento ativo, da valorização cultural e científica, do emprego e da competitividade económica para construir uma Europa forte e coesa em equilíbrio com uma sociedade intergeracional.

Retomando as questões a que nos propusemos dar resposta: que lugar tem a educação intergeracional na agenda europeia, na sociedade do conhecimento? Que influência tem nas políticas educativas nacionais?, e face ao que foi exposto anteriormente, estas são duas perguntas que não têm resposta clara e inequívoca se considerarmos, segundo Sáez Carreras (2002), que a educação intergeracional pode definir-se como "procesos y procedimientos que se apoyan y se legitiman enfatizando la cooperación y la interacción entre dos o más generaciones cualesquiera, procurando compartir experiencias, conocimientos, habilidades, actitudes y valores, en busca de sus respectivas autoestimas y personales autorrealizaciones" (p. 104).

Por último, no seguimento de uma investigação sobre o uso das tecnologias digitais da sociedade do conhecimento em contexto intergeracional, afirmamos que a promoção de dinâmicas intergeracionais com tecnologias digitais de informação e conhecimento permite intensificar as relações entre gerações, promover o envelhecimento ativo e perspetivar novas práticas de aprendizagem ao longo da vida.

"The acquisition of digital competence is an important element of supporting active ageing, opening up new learning opportunities for this group, either in formal or in informal settings. Using ICT is also a privileged means of learning while creating benefits across different generations, bringing young people and seniors together and tackling the digital divide" (European Commission, 2012, p. 5). 


\section{Referências}

Bardin, L. (2014). Análise de conteúdo. Lisboa: Edições 70.

Conselho da União Europeia (2012). Declaração do Conselho sobre o Ano Europeu do Envelhecimento Ativo e da Solidariedade entre as Gerações (2012): Perspetivas. Bruxelas.

Diário da República (8 de maio de 2012). Resolução da Assembleia da República n. ${ }^{\circ}$ 66/2012 - Recomenda ao Governo, no âmbito do Ano Europeu do Envelhecimento Ativo e da Solidariedade entre Gerações, Programa de Ação, 2012, o desenvolvimento de medidas concretas. $\left(1 .^{a}\right.$ série N. ${ }^{\circ}$ 89, p. 2427).

European Commission (2012). ICT for Seniors' and Intergenerational Learning. Projects funded through the Lifelong Learning Programme from 2008 to 2011. Brussels: Education, Audiovisual \& Culture Executive Agency

European Commission (2016). Communication from the Commission to the European Parliament, the Council, the European Economic and Social Committee and The Committee of the Regions a New Skills Agenda for Europe - working together to strengthen human capital, employability and competitiveness. Brussels, 10.6.2016. COM(2016) 381 final.

Governo de Portugal (2015). Programa do XXI Governo Constitucional 2015-2019.

Jornal Oficial da União Europeia (2015). Relatório conjunto de 2015 do Conselho e da Comissão sobre a aplicação do quadro estratégico para a cooperação europeia no domínio da educação e da formação (EF 2020) - Novas prioridades para a cooperação europeia no domínio da educação e da formação.

Ministério do Trabalho Solidariedade e Segurança Social (março de 2017). Relatório de Portugal do terceiro ciclo de revisão e avaliação da estratégia de implementação regional do Plano Internacional de Ação de Madrid sobre o Envelhecimento. Gabinete de Estratégia e Planeamento.

Saez Carreras, J. (2002). Hacia la educación intergeneracional. Concepto y posibilidades. En J. Saez (coord.), Pedagogía social y programas intergeneracionales: educación de personas mayores. Archidona (Málaga): Aljibe. 